\title{
A prática da responsabilidade socioambiental: estudo em uma empresa de biocombustíveis
}

Os atuais problemas socioambientais conquistaram um espaço de grande relevância entre os assuntos discutidos em nossa sociedade por serem causados em sua maior parte pela intervenção humana e por ameaçarem o equilíbrio ecológico do planeta e a existência de diversas formas de vida. Logo, hábitos e práticas de consumo sustentáveis poderão ocasionar a diminuição da quantidade de bens adquiridos e de resíduos gerados pós-consumo, contribuindo para a preservação ambiental. Nesse sentido, o biodiesel se apresenta como uma alternativa sustentável aos combustíveis fósseis por ser considerado um combustível biodegradável, derivado de fontes renováveis como óleos vegetais puros ou já utilizados e de gordura animal. Assim considerando a importância destas organizações que produzem biodiesel para a sustentabilidade no âmbito ambiental e social, este estudo buscou descrever como uma organização que considerando a importância destas organizações que produzem biodiesel para a sustentabilidade no âmbito ambiental e social, este estudo buscou descrever como uma organização que
produz biocombustíveis coloca em prática a responsabilidade socioambiental nas comunidades onde atua. Para isso, realizou-se uma pesquisa de abordagem qualitativa do tipo estudo de caso na qual se entrevistou o Gestor (sócio administrador) de uma pequena empresa que produz biocombustíveis estabelecida em um município localizado na região Sul de Minas Gerais. Utilizou-se como método de coleta de dados a entrevista semiestruturada e para análise, o método de categorização de dados. Ao final, constatou-se práticas significativas como a implantação de um processo produtivo que prioriza os princípios da ecoeficiência, o trabalho junto ao poder público para o estabelecimento de medidas voltadas para o descarte consciente do óleo vegetal e animal na região e ações para a sensibilização das comunidades. Percebeu-se ainda, ao analisar os relatos do Gestor entrevistado, que esta organização privilegia o paradigma integrador da sustentabilidade que busca o crescimento econômico sem causar grandes impactos ao meio ambiente.

Palavras-chave: Sustentabilidade; Responsabilidade socioambiental; Práticas de sensibilização.

\section{The practice of socio-environmental responsibility: study in a biofuel company}

\begin{abstract}
The current socio-environmental problems have conquered a space of great relevance among the issues discussed in our society because they are mostly caused by human intervention and because they threaten the ecological balance of the planet and the existence of different forms of life. Therefore, sustainable consumption habits and practices may cause a decrease in the amount of goods purchased and waste generated after consumption, contributing to environmental preservation. In this sense, biodiesel presents itself as a sustainable alternative to fossi fuels because it is considered a biodegradable fuel, derived from renewable sources such as pure or already used vegetable oils and animal fat. Considering the importance of these organizations that produce biodiesel for environmental and social sustainability, this study aim to describe how an organization that produces biofuels putting the socio-environmental organizations that produce biodiesel for environmental and social sustainability, this study aim to describe how an organization that produces biofuels putting the socio-environmental
responsibility into practice in the communities where it operates. A qualitative research of the case study type was carried out in which the Manager (managing partner) of a small company responsibility into practice in the communities where it operates. A qualitative research of the case study type was carried out in which the Manager (managing partner) of a small company
that produces biofuels was interviewed, established in a municipality located in the southern region of Minas Gerais. The semi-structured interview was used as the data collection method and the data categorization method was used for analysis. The significant practices were found, such as the implementation of a production process that prioritizes the principles of ecoefficiency, work with the government to establish measures aimed at the conscious disposal of vegetable and animal oil in the region and actions to raise awareness. Of communities. It was also noticed, when analyzing the reports of the Manager interviewed, that this organization privileges the integrating paradigm of sustainability that seeks economic growth without causing major impacts to the environment.
\end{abstract}

Keywords: Sustainability; Socio-environmental responsibility; Awareness-raising practices.

Topic: Responsabilidade Socioambiental Corporativa

Reviewed anonymously in the process of blind peer.

Pablo Christian de Moro Silva (iD)

Universidade Vale do Rio Verde de Três Corações, Brasil

http://lattes.cnpq.br/8954112889309575

http://orcid.org/0000-0002-6090-5106

prof.pablo.silva@unincor.edu.br

Fabiana Miranda Muniz (iv)

Universidade Vale do Rio Verde de Três Corações, Brasil

http://lattes.cnpq.br/4141348272507747

http://orcid.org/0000-0002-9602-8934

prof.fabiana.muniz@unincor.edu.br

Mayara Gabriela Lourenço Ferreira (iD)

Universidade Vale do Rio Verde de Três Corações, Brasil

http://lattes.cnpq.br/4861166404458036

http://orcid.org/0000-0002-6712-7896

prof.mayara.lourenco@unincor.edu.br

d

DOI: 10.6008/CBPC2179-6858.2021.006.0058
Received: 05/06/2021

Approved: 26/06/2021

\section{Letícia Rodrigues da Fonseca (id) \\ Universidade Vale do Rio Verde de Três Corações, Brasil \\ http://lattes.cnpq.br/4847209046603133 \\ http://orcid.org/0000-0002-3528-2090 \\ leticia.rodrigues.vga@gmail.com}

Daiane Fernandes Pereira Lahmann (iD)

Universidade Vale do Rio Verde de Três Corações, Brasil

http://lattes.cnpq.br/6972291289092668

http://orcid.org/0000-0002-0111-6094

daianeviannajr@yahoo.com.br
Referencing this:

SILVA, P. C. M.; MUNIZ, F. M.; FERREIRA, M. G. L.; FONSECA, L. R.; LAHMANN, D. F. P.. A prática da responsabilidade socioambiental: estudo em uma empresa de biocombustíveis. Revista Ibero Americana de Ciências Ambientais, v.12, n.6, p.706-719, 2021. DOI: http://doi.org/10.6008/CBPC2179-6858.2021.006.0058 


\section{INTRODUÇÃO}

Os atuais problemas socioambientais conquistaram um espaço de grande relevância entre os assuntos discutidos em nossa sociedade por serem causados em sua maior parte pela intervenção humana e por ameaçarem o equilíbrio ecológico do planeta e a existência de diversas formas de vida. No entanto, a natureza continua a ser vista como uma simples fonte de recursos ou um local de depósito de resíduos das atividades humanas e empresariais (SILVA et al., 2011).

Devido a este cenário, a sustentabilidade passou a ser tratada como uma estratégia para atender aos propósitos de crescimento econômico, preservação ambiental e melhoria da qualidade de vida da sociedade de modo simultâneo (MEADOWS et al., 1992).

São inúmeras as iniciativas voluntárias de grandes corporações voltadas para o desenvolvimento sustentável como forma de atender as três dimensões da sustentabilidade (econômica, ambiental e social). Entretanto, estes esforços ainda não conseguiram satisfazer, de modo igualitário, as demandas existentes nestas três esferas (BARBIERI, 2006). Logo, hábitos e práticas de consumo sustentáveis poderão ocasionar a diminuição da quantidade de bens adquiridos e de resíduos gerados pós-consumo, contribuindo para a preservação ambiental.

A busca por alternativas para substituição dos combustíveis fósseis tem se intensificado pelo fato de muitos países apresentarem receio de dependerem daqueles que são detentores de reservas de petróleo bruto e por este tipo de combustível impactar negativamente o meio ambiente. Cita-se, como exemplo, o dióxido de carbono que é liberado durante a queima deste combustível e que contribui, significativamente, para a poluição (PACHECO et al., 1990). Sendo assim, o biodiesel se apresenta como uma alternativa sustentável aos combustíveis fósseis por ser considerado um combustível biodegradável, derivado de fontes renováveis como óleos vegetais puros ou já utilizados e de gordura animal.

Considerando a importância destas organizações que produzem biodiesel para a sustentabilidade no âmbito ambiental e social, este estudo buscou, como objetivo principal, descrever como a responsabilidade socioambiental foi efetivada por uma pequena empresa de biocombustíveis, instalada em um município da região sul de Minas Gerais. No desenvolver de suas atividades econômicas, o empreendimento se pautou na utilização específica de óleos vegetais e animais que eram recolhidos diretamente nas casas dos moradores. Posteriormente, estendeu as suas atividades para outros municípios da região.

Ressalta-se que a efetivação de práticas voltadas para a responsabilidade socioambiental é extremamente significativa a partir do momento que despertam nos funcionários e comunidades envolvidos, o interesse pelos problemas ambientais e sociais que ocorrem na organização ou além de seus muros.

\section{REVISÃO TEÓRICA}

\section{Responsabilidade socioambiental}

O crescimento econômico mundial impulsionou a ocorrência de problemas ambientais que por volta de 1962, eram ignorados e, quando abordados, eram superficialmente. Mudanças em relação à percepção, 
com a proposição de ações estratégias, datam do início de 1968 e se intensificaram nas últimas duas décadas do século XX, quando o assunto acerca do cuidado ambiental foi pauta de discussões entre nações e foco de encontros mundiais (AMATO NETO, 2015).

A partir de então, as organizações modernas começaram a agir para minimizar o impacto ambiental. Iniciou-se a propagação da conscientização ecológica no mundo dos negócios, motivada pelas normas legais e criação de órgãos que as regulam (AMATO NETO, 2015). Na atualidade, as avaliações que consideram o desenvolvimento econômico de uma nação se atentam ao seu impacto sobre a sociedade e o meio ambiente (JONES et al., 2018).

Assim, o cuidado ambiental exigido pelas organizações passou a envolver não somente o ambiente natural, mas também as pessoas que o habitam - o que fez surgir a inter-relação do social com o ambiental e, então, o fenômeno nomeado como responsabilidade socioambiental (RSA) das organizações (BIER et al., 2015). Esta inter-relação inaugurou-se como um paradigma universal e como fundamento para frear os danos ambientais, resultantes da constante e inesgotável busca pelo crescimento econômico (JONES et al., 2018).

A RSA não deve ser concebida enquanto política organizacional, mas compreendida enquanto ética global, que favorece a relação entre a organização com o meio ambiente e com os seus stakeholders, sendo estes últimos, direta ou indiretamente afetados por ela (COHEN et al., 2017).

De acordo com Cordazzo et al. (2018), muitos avanços são registrados em torno do tema de RSA; entretanto, na mesma proporção, ainda há desentendimentos e desacordos acerca de sua aceitação por parte de alguns segmentos de negócios. Silva et al. (2020a), afirmam que todas as empresas, independente do segmento e porte, estão, direta ou indiretamente, envolvidas com questões pertinentes à sustentabilidade. Entretanto, Fenker et al. (2015), ponderam que as empresas de médio e grande porte são as que mais investem em responsabilidade social coorporativa e gestão ambiental devido ao impacto de suas atividades no meio ambiente e, consequentemente, na sociedade.

Portella et al. (2015) afirmam que, de forma geral, todas as organizações deveriam enxergar pelo menos três motivos para buscar a melhoria no desempenho ambiental organizacional: a exigência crescente de proteção ambiental resguardada pela legislação internacional; as novas exigências do mercado; o conhecimento produzido a partir de novas descobertas relacionadas às causas versus impactos dos danos ambientais.

Para Mintzberg (2015), alguns segmentos acreditam que a RSA se resume em cumprir leis e normas de preservação do meio ambiente. Este é um dos objetivos; contudo, não o único, sendo que a responsabilidade vai além desta obediência e se estende ao compromisso com a mudança requisitada pelas políticas e cultura social que buscam a preservação do meio ambiente para as futuras gerações.

Munck (2013) corrobora com o pensamento de Mintzberg (2015), e acresce que a mudança deve se iniciar na gestão organizacional e se estender aos colaboradores. Nesta nova cultura, as organizações precisam estreitar seus relacionamentos com a comunidade e com órgãos governamentais ambientais. E, ainda, cuidar da definição das práticas que possam demonstrar aos stakeholders os compromissos em prol 
da sustentabilidade, haja vista que as questões ambientais, na atualidade, estão relacionadas aos valores de cada negócio.

Mesmo com a contemporaneidade do tema e com a exaustão literária que o aborda, inexiste um conceito único para a RSA, sendo o termo comumente associado à concepção de que as organizações precisam estar atentas aos impactos que suas atividades ocasionam aos seus entornos (DOMINGUES et al., 2020).

Para Zhao et al. (2017), implica na integração voluntária de questões sociais e ambientais na rotina das organizações e nas relações entre as partes envolvidas e interessadas, sendo necessário, às vezes, sacrificar lucros para beneficiais interesses sociais.

Para Donaire (2016), implica na incorporação de características sociais em produtos e processos de produção associadas à preservação ambiental. Já para Souza et al. (2017), refere-se às práticas organizacionais centradas no lucro sem se distanciar de ações sustentáveis, voltadas aos stakeholders, pautadas no compromisso em resolver problemas sociais.

Assim, o critério de responsabilidade promoveu uma nova classificação das organizações, enquadrando-as em três modelos distintos: organizações pretenciosas ao lucro e assumidas como negócios; organizações que consideram a satisfação dos interesses sociais; e organizações pretensiosas ao lucro, que consideram a satisfação dos interesses sociais e promovem ações voltadas à conservação ambiental (RIBEIRO et al., 2017).

Na prática, as organizações possuem dificuldades para praticar a responsabilidade social integrada à responsabilidade ambiental, mesmo que ambas as dimensões sejam funcionais e ativas nas atividades diárias. O exercício desta integração, denominada como sustentabilidade, registra-se como recente (FENKER, et al., 2015).

Foi em tal cenário sustentável de responsabilização das organizações que alguns termos socioambientais surgiram, inclusive originando o conceito de sustentabilidade. Teoricamente, tem-se um consenso de que seja um equilíbrio entre os benefícios mútuos, considerando pessoas e comunidade e a conservação dos recursos naturais, cuja finalidade é garantir a sobrevivência de seres humanos, no presente e no futuro (MUNCK, 2013; FENKER et al., 2015; MINTZBERG, 2015; DONAIRE, 2016). Ainda, de acordo com Campos et al. (2015), como "[...] um conceito sistêmico que visa suprir todas as necessidades sociais, econômicas, culturais e ambientais para garantir um futuro melhor, [...] com o uso de recursos naturais de forma inteligente e protegidos pensando na geração futura".

Na prática, no âmbito organizacional, o termo sustentabilidade é atribuído ao equilíbrio demandado entre os aspectos econômico-social-ambiental. Estes foram caracterizados enquanto dimensões por Elkington (1994), e definidos como o Triple Bottom Line (TBL) - ou Tripé da Sustentabilidade (MUNCK, 2013; FENKER et al., 2015; MINTZBERG, 2015; DONAIRE, 2016). Assim, ao se falar em sustentabilidade nas organizações, aborda-se de forma automática o modelo TBL e seus 3P's profit-people-planet. É justamente por meio da combinação destas dimensões que as organizações podem se caracterizar como financeiramente viáveis, ambientalmente corretas e socialmente justas e, consequentemente, rentáveis, 
sustentáveis e lembradas, considerando sua reputação social e ambiental (LOPES et al., 2017).

A partir da formulação conceitual de sustentabilidade, associado à proposta do TBL, definiu-se o papel "da responsabilidade" das organizações na sociedade (BIER et al., 2015) - o de ressarcir aos afetados, por meio da promoção de práticas contribuintes para melhoria contínua do meio ambiente e da qualidade de vida (RIBEIRO et al., 2015).

A implementação da RSA nas atividades organizacionais, faz com que o contexto envolvido impactado passe a perceber as novas atitudes das organizações em relação ao equilíbrio necessário entre crescimento econômico, desenvolvimento da sociedade e conservação do meio ambiente (DONAIRE, 2016) - o que irá ocasionar benefícios significativos como: acesso ao mercado de capitais, melhor aproveitamento de recursos e melhoria da imagem institucional (FENKER et al., 2015).

Em síntese, a implementação da RSA possibilita uma melhoria contínua para a sociedade e meio ambiente, tornando a organização um agente de mudança, em parceria com a sociedade civil e com o Estado. É uma atitude esperada, ao considerar a sociedade atual que prioriza a melhoria da qualidade de vida (MUNCK, 2013; MINTZBERG, 2015).

A nova cultura de responsabilidade caracteriza as organizações como sustentáveis ou responsáveis, considerando que as suas ações são freadas em relação aos impactos negativos das atividades (CORDAZZO et al., 2018). Para tanto, espera-se de sua gestão um planejamento estratégico eficiente e competitivo, já que as organizações que não adotam a nova postura (responsável e sustentável) estão perdendo espaço no mercado em detrimento àquelas que estão se adequando à essa nova demanda (AMATO NETO, 2015).

Zhao et al. (2017) afirmam que as organizações que não possuem metas e objetivos estratégicos relacionados à RSA estão suscetíveis às dificuldades de sobreviver em meio às demais que alinharam a teoria da sustentabilidade com a prática, não somente devido ao fortalecimento de imagem adquirido por estas, mas por não atenderem às determinações legais.

As organizações responsáveis definem-se como aquelas que promovem bem-estar social e humano, minimizando impactos ecológicos e assegurando, concomitantemente, o êxito de seus objetivos (AMATO NETO, 2015). Por isso, exploram rótulos que as diferenciam no mercado, tais como: organizações com ética em seus negócios; em conformidade legal; filantrópicas, sustáveis; com investimentos em comunidades relacionadas; que respeitam os direitos humanos; que praticam gestão de stakeholders; dentre outros (ZHAO et al., 2017).

Esta cultura diferenciada adotada, geradora de lucros e propulsora da economia regional, cuja prática respeita seus stakeholders, pautando-se em políticas ambientais e mudanças organizacionais, corrobora para a promoção de um discurso de RSA que se integra em suas estratégias (JONES et al., 2018). O grau de responsabilidade adotado por tais organizações é determinante para a sua imagem e identidade frente ao mercado (SILVA et al., 2020a), servindo como elemento para o julgamento público e critério para investidores, consumidores e colaboradores de uma organização (PORTELLA et al., 2015).

A implantação da RSA nas organizações implica em benefícios mútuos e vantagens competitivas, incluindo vantagem de marketing (SILVA et al., 2020b). O investimento em políticas sustentáveis transparece 
ao público de uma marca a sua ética, compromisso e credibilidade (DOMINGUES et al., 2020). Pode-se afirmar então, que a RSA corrobora para o capital reputacional de uma organização (MACHADO FILHO, 2006) - conforme esquematizado pela Figura 1, que segue, por meio de um esboço de modelo para a criação de valor a partir de uma conduta socialmente responsável.

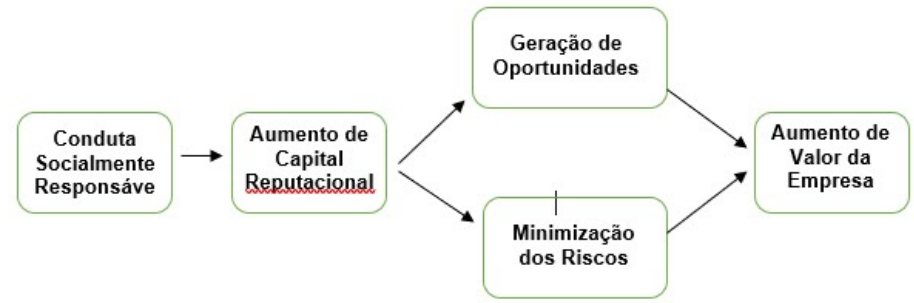

Figura 1: Modelo para a criação de valor a partir de uma conduta socialmente responsável. Fonte: Machado Filho (2006).

Acrescenta-se que o capital reputacional é um regulatório do mercado, que evidencia a conscientização e o valor de uma organização que tem condutas socialmente responsáveis, ocasionando oportunidades de mercado. Quanto mais apresenta-se e pratica-se a conduta responsável, mais se minimizariscos e se potencializa a reputação; obtendo um maior valor de mercado (MACHADO FILHO, 2006).

Ainda, para prevenção de imputações penais ou para valorização do capital reputacional, comumente são contratadas consultorias especializadas no assunto para análises e auditorias que possam identificar ameaças e oportunidades e propor ações socioambientais que corroborem com a efetivação do trabalho responsável. Tais consultorias, têm por finalidade a promoção (por meio de práticas sociais e ambientais) da manutenção da saúde financeira da organização e, para tanto, cuidam do sucesso dos negócios frente à necessidade de cumprimento da responsabilidade com o meio ambiente e com a sociedade (LOPES et al., 2017).

Assim, as organizações devem priorizar as práticas que favorecem a RSA, transparecendo as iniciativas e superando as limitações. Em consenso, tem-se a afirmação de que tais ações demonstrativas não são equivalentes aos princípios socioambientais preconizados, mas às práticas adotadas mediante políticas reativas, preventivas ou proativas adotadas, a partir do estágio em que as organizações se encontram mediante auditorias realizadas (BEREZAN et al., 2013; RIBEIRO et al., 2015; CORREIA et al., 2017; PAIVA et al., 2019; SILVA et al., 2020b).

As práticas adotadas, a partir das políticas estabelecidas, podem ser classificadas em três estágios, sendo: primeiro estágio, práticas reativas - consideradas a partir de propostas de ações que atendam à legislação ou normas, além do atendimento aos requisitos do produto e, por isso, representam a busca por respostas esperadas pela organização; segundo estágio, práticas preventivas - consideradas a partir dos impactos gerados, mediante ações emergenciais para o alcance dos objetivos da organização e; terceiro estágio, práticas proativas - consideradas a partir da postura ativa e inovadora da gestão da organização, caracterizando-se como ações voluntárias que visam assegurar a sustentabilidade à longo prazo (CORREIA et al., 2017; PAIVA et al., 2019; SILVA et al., 2020a).

As práticas planejadas, a partir de políticas formuladas, enquanto resultante de auditorias e 
consultorias, devem partir da gestão; contudo, estendidas para os colaboradores operacionais, sendo de responsabilidade dos mesmos a efetivação das mudanças de processos e ações cotidianas planejadas pelos gestores (BEREZAN et al., 2013; RIBEIRO et al., 2015; LOPES et al., 2017).

A partir das práticas adotadas e do funcionamento das políticas, à longo prazo é possível proceder com a mensuração do alcance das ações sociais e ambientais formuladas pelas organizações, principalmente para a avaliação do desempenho e impactos econômicos, sendo estes primordiais para a continuidade das atividades e manutenção no mercado competitivo (LOPES et al., 2017).

A mensuração do alcance das ações sociais e ambientais adotadas e praticadas por qualquer instituição, necessita de instrumentos/indicadores adequados e se caracteriza como um fenômeno complexo, pela necessidade de abordar o TBL (BOTELHO et al., 2015; FIGUEIREDO et al., 2016; ALMEIDA et al., 2017; RODRIGUES et al., 2017; PAIVA et al., 2019; SILVA et al., 2020a; DOMINGUES et al., 2020). Além disso, para mensuração, faz-se necessário que qualquer organização forneça informações que viabilizem as avaliações - ou seja, demanda-se pela prática do disclosure (LOPES et al., 2017).

Botelho et al. (2015) definem os indicadores de RSA como instrumentos disponíveis para as organizações, cujo uso tem por finalidade o direcionamento das estratégias para buscas constantes de vantagens competitivas. Almeida et al. (2017) corroboram com a definição e acrescentam que se configuram como critérios para orientação da gestão quando esta pretende planejar políticas e ações a serem praticas pela organização.

Dentre os indicadores, o Balanço Social é um dos mais destacados pelos gestores. Figueiredo et al. (2016) afirmam que este indicador pode ser considerado como um instrumento que serve para ampliação da comunicação entre a organização e os seus públicos de interesses (ou stakholdes).

Além da comunicação, para Silva et al. (2020b), o Balanço Social evidencia o grau de envolvimento da organização com seus públicos de interesse, vindo a construir ou fortalecer o elo existente entre empresa e sociedade. Em conformidade, os autores ponderam que este indicador objetiva orientar as avaliações de mercado, órgãos de financiamento e analistas de mercado quanto ao compromisso da organização com a RSA.

Botelho et al. (2015) destacam o Instituto Ethos de Responsabilidade como um instrumento de avaliação, que faz uso das dimensões: social; ambiental; governança e gestão e; visão e estratégia. Os indicadores do referido instituto focam na avaliação quantitativa da RSA para definição de novas estratégias, políticas e processos em uma organização. Os mesmos indicadores são apontados por Cordazzo et al. (2018), ao destacarem o Grupo de Reflexão e Apoio à Cidadania Empresarial (GRACE) como instrumento para avaliações de empresas brasileiras.

Destaca-se ainda o Global Reporting Initiative (GRI), considerado um indicador mundialmente utilizado (RODRIGUES et al., 2017). De acordo com Paiva et al. (2019), o modelo para produção de relatórios criado pelo grupo vem sendo difundido para a evidenciação do desempenho no âmbito ambiental, social e econômico, principalmente quando se busca a prestação de contas para os stakholders por prezarem pela sustentabilidade, já que são dotados de descrições detalhadas acerca dos investimentos socioambientais 
realizados. O GRI se difere do Balanço Social pois preza pela qualidade das informações prestadas em detrimento à quantidade.

Lopes et al. (2017) e Silva et al. (2020a) consideram o Índice de Sustentabilidade Empresarial (ISE) como um índice de RSA. Seu objetivo é promover um ambiente de investimentos compatíveis com a demanda do desenvolvimento sustentável, estimulando a responsabilidade de organizações, a partir: da justiça social; da eficiência econômica e; do equilíbrio ambiental.

Todos os indicadores citados podem ser utilizados pelas organizações na contemporaneidade, sendo eficientes para o fornecimento de informações que possam promover avaliações acerca das relações que se tem com o meio ambiente. Segundo Lopes et al. (2017), a evidenciação de informações socioambientais é uma das exigências relacionadas à transparência das atividades organizacionais, ao mesmo passo que possibilita a redução da assimetria informacional junto aos seus stakholders.

Frente ao exposto, afirma-se que a RSA se insere em organizações que adquirem maturidade, profissionalização de processos e que buscam por modos produtivos e seguros para a sociedade e o meio ambiente.

\section{MATERIAIS E MÉTODOS}

Considerando o objetivo principal proposto para este estudo, optou-se por realizar uma pesquisa de abordagem qualitativa do tipo exploratória e descritiva, que possibilitou compreender o fenômeno investigado em sua complexidade a partir de relatos que permitiram compreender as relações sociais e culturais presentes no contexto investigado (BERTUCCI, 2009).

Para Berg (2001), a pesquisa qualitativa responde perguntas pela investigação de ambientes sociais. Ela possibilita ao pesquisador, compartilhar das compreensões e percepções dos indivíduos que habitam esses ambientes, como interpretar o comportamento das pessoas e os significados que atribuem às situações vivenciadas.

Como instrumento de coleta de dados fez-se uso da entrevista semiestruturada cujo roteiro foi elaborado a partir do arcabouço teórico que subsidiou o desenvolvimento da pesquisa, sendo constituída por um conjunto de questões pré-estabelecidas que visam auxiliar o pesquisador em seu propósito de compreender os significados que os indivíduos atribuem às questões e situações relacionadas ao fenômeno investigado, pela análise de dados descritivos, coletados em seus discursos (GODOY, 2006).

Foi entrevistado o Gestor (sócio administrador) de uma pequena empresa de produção de biocombustível estabelecida em um município da região sul de Minas Gerais, que iniciou suas atividades em 2008. É importante ressaltar que esta empresa foi adquirida por uma outra corporação e não atua mais neste município desde 2016. Os relatos foram gravados e posteriormente transcritos.

Utilizou-se como método de análise de dados a categorização que consiste em definir do que se trata os dados em análise, envolvendo a identificação e o registro de uma ou mais passagens de texto, como partes de um quadro geral que, em algum sentido, exemplificam a mesma ideia teórica e descritiva. Geralmente, várias passagens são identificadas e relacionadas com uma ideia. Sendo assim, todo o texto, entre outros 
elementos, que se refere à mesma ideia ou exemplifica a mesma ideia é agrupado e codificado com o mesmo nome. A codificação é uma forma de indexar ou categorizar o texto para se estabelecer uma estrutura de ideias temáticas em relação a ele (GIBBS, 2009).

\section{RESULTADOS E DISCUSSÃO}

Nesta seção são apresentados os resultados que foram obtidos segundo as categorias (ou tópicos) estabelecidas conforme o método de análise utilizado neste estudo.

\section{Entendimento do conceito de responsabilidade socioambiental}

Neste estudo, buscou-se compreender o entendimento que o Gestor da organização investigada possuía acerca da responsabilidade socioambiental. De acordo com o relato do entrevistado: "Entendo que responsabilidade socioambiental tem a ver com conscientização geral sobre sustentabilidade ambiental e práticas para atingir a este fim, preservando e recuperando o meio ambiente, sem deixar de desenvolver as atividades necessárias ao ser humano".

Percebe-se que este gestor possui um correto entendimento acerca do conceito de responsabilidade socioambiental que se refere às responsabilidades que uma organização possui com a sociedade e com o meio ambiente, além das obrigações legais e econômicas que necessitam ser cumpridas, ou seja, além do cumprimento de determinações legais e financeiras, é preciso que a empresa estabeleça estratégias, programas e ações que possam favorecer a sociedade e o meio ambiente (MAZZUOLI et al., 2012).

Entretanto, como a ausência da responsabilidade socioambiental pode impactar as organizações por meio de sansões administrativas ou civil (SOUZA et al., 2017), buscou-se averiguar se está regulação seria o principal motivo para a prática da responsabilidade socioambiental nesta organização. De acordo com o entrevistado:

Os gestores têm o importante papel de educar para elevar o nível de vida, estabelecer um sentido mais forte de responsabilidade em relação ao meio ambiente, preocupar-se com as questões éticas, com o entusiasmo e a vontade de viver juntos, aceitar e tolerar as diferenças e enfrentar as dificuldades no desenvolvimento da sociedade (ENTREVISTADO GESTOR).

Percebe-se, por meio do discurso deste Gestor, que a prioridade é contribuir para o atendimento das necessidades ambientais e sociais, não sendo as obrigações legais o principal incentivo para a prática da responsabilidade socioambiental o que não é comum, já que as organizações tendem a priorizar o crescimento econômico e a eliminação das barreiras que possam comprometê-lo.

\section{Ações Voltadas para a Responsabilidade Socioambiental}

Buscou-se identificar os tipos de estratégias e ações que esta organização que produz biodiesel colocava em prática para atender os propósitos da responsabilidade socioambiental. Neste momento, o entrevistado destacou que a própria atividade da empresa contribui para a conservação do meio ambiente e, consequentemente, para a sociedade. Entretanto, a comunidade local por não ter este entendimento não se envolvia, inicialmente, nas ações voltadas para a coleta de óleo: 
O início foi muito desgastante, pois os moradores do município não tinham conhecimento da atividade da empresa e dos benefícios ao meio ambiente de se separar o óleo já utilizado e entregá-lo a uma empresa que faria a coleta seletiva desse resíduo, e muitas vezes nem nos deixava esclarecer do que se tratava; daí me veio à cabeça a ideia de fazer palestras e programas de conscientização nas escolas, e não ficou só por aí (ENTREVISTADO - GESTOR).

Solicitou-se a este Gestor que discorre um pouco mais sobre este projeto de conscientização, bem como sobre o seu propósito:

[...] a alternativa foi buscar espaços em escolas do ensino fundamental e do ensino médio, para mudar o pensamento dos mais jovens buscando embutir o pensamento crítico sobre suas atitudes quanto ao meio ambiente, com intuito de que os mesmos levassem esses questionamentos para dentro de suas casas, inclusive, discorrendo sobre o prejuízo do descarte de óleo no esgoto e nas águas (ENTREVISTADO - GESTOR).

Como essa sensibilização poderia favorecer a atividade desta organização, buscou-se averiguar se esta ação foi instituída como uma estratégia de negócio voltada para o crescimento econômico. Segundo o Gestor:

Desde o início tínhamos mais preocupação com o desenvolvimento de consciência da população em geral quanto às questões de sustentabilidade e responsabilidade socioambiental do que, necessariamente, com o sucesso financeiro, não que este não fosse importante. Dentro do que tínhamos à disposição, vejo que nossa estratégia foi exitosa. Houve sim, na cidade, maior conscientização, mas temo que tenha se perdido pela falta de continuidade do trabalho, já que a empresa foi vendida para outro grupo (ENTREVISTADO GESTOR).

Novamente o entrevistado ressalta que as práticas de responsabilidade socioambiental possuem, como principal objetivo, contribuir para o desenvolvimento das comunidades nas quais a organização está inserida, no entanto, indiretamente, também favorecem o âmbito financeiro. O entrevistado evidencia ainda, a sua preocupação quanto à permanência desta conscientização nas comunidades, já que a organização foi adquirida por outro grupo empresarial de outro estado, o que impediu a continuidade deste projeto.

A conscientização ambiental surge a partir da sensibilização que é ocasionada quando o indivíduo tem acesso a informações acerca de determinadas situações que o levam a refletir sobre o seu comportamento. Este movimento ocorre por meio da Educação Ambiental que é "cultural e informativa, mas fundamentalmente política, formativa e emancipatória, portanto, transformadora das relações sociais existentes" (LOUREIRO, 2012), causando o rompimento de padrões vigentes na sociedade e impondo processos que permitem o exercício dos indivíduos de se colocarem no lugar de seus próximos. Entretanto, para que este objetivo seja alcançado é preciso que a sensibilização seja fortalecida por meio do incentivo, para que se possa obter de fato a conscientização dos indivíduos, levando-os a adotar outros comportamentos. Logo, diante do contexto apresentado, possivelmente o trabalho de sensibilização e conscientização foi comprometido devido à ausência de incentivos, já que as atividades da organização investigada foram encerradas na região.

Ao ser questionado se as ações da organização foram além destes debates e palestras nas escolas, o entrevistado alegou:

[...] nossas atividades se estenderam por cerca de 20 municípios da região; e como não existia legislação estadual conscientizando ou obrigando do descarte consciente do óleo vegetal e animal usados, eu fui pessoalmente à várias Câmaras municipais buscando elaboração de projetos de leis municipais neste sentido (ENTREVISTADO - GESTOR). 
Sobre a efetividade e dificuldades enfrentadas durante a sua intervenção junto ao legislativo municipal, este gestor relatou que: "Não foi fácil, mas consegui implementar em alguns municípios estes projetos de lei, que foram aprovados em alguns deles e hoje a população daqueles municípios possuem regramento para descarte do óleo".

Logo, percebe-se que a responsabilidade socioambiental se trata de uma ação conjunta entre a sociedade civil, empresas e governos locais. Como informado pelo Gestor da empresa, a busca pela atuação estatal se deu com o objetivo de aprimoramento da gestão e da implementação de política pública social, que pode incentivar os cidadãos à exercerem a solidariedade e assumirem atitudes comportamentais éticas e as empresas, por sua vez, devem ser responsáveis pela produção e oferta de seus serviços de maneira ética, sem comprometer as gerações futuras (MEADOWS et al., 1992).

Questionou-se ainda, se a organização implementou alguma ação em seu ambiente interno com o intuito de zelar pelo bem-estar da comunidade na qual está inserida e pela preservação ambiental. De acordo com o depoimento do entrevistado:

Recebemos várias visitas de funcionários da Petrobras exatamente pela forma de nossa produção, pois eles buscavam entender como conseguíamos produzir sem gerar resíduos. Além de nosso projeto ter sido pioneiro, nossa produção não gerava resíduos, por isso não nos preocupávamos com descarte ou aproveitamento (ENTREVISTADO - GESTOR).

Percebe-se que esta organização segue os princípios da ecoeficiência por não gerar resíduos ou por gerar uma pequena quantidade em seu processo produtivo. A ecoeficiência ocorre quando processos produtivos possibilitam a entrega de mercadorias e serviços a preços competitivos, que satisfazem as necessidades humanas e que favorecem a qualidade de vida por reduzirem os impactos ecológicos e o uso de recursos naturais como matéria-prima (SCHMIDHEINY, 1992).

Nesta discussão, emerge ainda o conceito de organizações inovadoras sustentáveis que são caracterizadas como aquelas que criam valor de longo prazo aos acionistas ou proprietários e que buscam desenvolver soluções para os problemas ambientais e sociais por meio de inovações (BARBIERI, 2007). Neste sentido, pode-se também caracterizar a organização foco deste estudo como "inovadora e sustentável".

Portanto, por meio das análises realizadas, acredita-se que esta organização segue os princípios do paradigma integrador da sustentabilidade que busca o desenvolvimento econômico sem causar grande impacto no meio ambiente, além de contribuir para a melhoria da qualidade de vida da sociedade, principalmente, das comunidades nas quais está inserida (BARBIERI, 2007).

\section{CONCLUSÕES}

O ideal desenvolvimentista almejado inicialmente, caracterizado pelo progresso e um discurso capitalista, tornou-se inviável devido ao impacto que este crescimento econômico ocasionou na biodiversidade natural. É inquestionável que o desenvolvimento industrial adotado nos últimos 200 anos proporcionou riqueza e prosperidade, entretanto, também causou degradação ecológica não intencional, gerando inúmeros problemas ambientais (SACHS, 1986).

Devido ao desenvolvimento da legislação ambiental que regula as atividades empresariais quanto 
aos impactos no meio ambiente e a cobrança da sociedade que exige a redução e compensação por estes impactos gerados, as organizações vêm buscando desenvolver práticas ambientalmente salubres que possibilitem a preservação ambiental sem comprometer a produtividade e competitividade, bem como, a melhoria da qualidade de vida da sociedade (FUSS et al., 2018).

Logo, o cuidado ambiental exigido passou a envolver não somente o ambiente natural, mas também as pessoas que o habitam - o que fez surgir a inter-relação do social com o ambiental e, então, o fenômeno nomeado como responsabilidade socioambiental (RSA) nas organizações (BIER et al., 2015).

Neste estudo foi possível averiguar práticas significativas que envolvem a responsabilidade socioambiental praticadas pela organização foco deste estudo, cuja atividade principal - fabricação de biocombustível - contribui significativamente para a preservação ambiental.

Cita-se a busca por implantar um processo produtivo que prioriza os princípios da ecoeficiência, o trabalho junto ao poder público para o estabelecimento de medidas voltadas para o descarte consciente do óleo vegetal e animal na região em que a organização está inserida e as ações para a sensibilização das comunidades, como palestras realizadas nas escolas de educação básica que buscam debater questões acerca da importância da preservação do meio ambiente e o papel do setor privado e da sociedade como um todo para que este objetivo seja atingindo.

Destaca-se que o entendimento do gestor sobre responsabilidade socioambiental e as ações relatadas, evidenciam que esta empresa busca colocar em prática o paradigma integrador da sustentabilidade o que não é algo comum, já que muitas organizações tendem a privilegiar o paradigma antropocêntrico que prioriza o crescimento econômico, em vez de atender, igualmente, as dimensões econômicas, ambientais e sociais da sustentabilidade.

Quanto às limitações deste estudo, cita-se a utilização de apenas um método de coleta de dados e o envolvimento de um único colaborador que se deu devido a aquisição da empresa analisada por outro grupo empresarial. Acredita-se que o uso de outros métodos de coleta de dados - como análise documental e observação participativa - e o envolvimento de outros colaboradores, poderia complementar os dados adquiridos. Logo, recomenda-se que pesquisas futuras com o mesmo propósito de estudo sejam realizadas para validar ou complementar os resultados aqui expostos, inclusive na mesma empresa investigada que pertence a outro grupo empresarial.

\section{REFERÊNCIAS}

ALMEIDA, K. K. N.; CALLADO, A. L. C.. Indicadores de desempenho ambiental e social de empresas do setor de energia elétrica brasileiro: uma análise realizada a partir da ótica da Teoria Institucional. Revista de Gestão, Finanças e Contabilidade, v.7, n.1, p.222, 2017. DOI: https://doi.org/10.18028/2238-5320/rgfc.v7n1p222-239

AMATO NETO, J.. A era do ecobusiness: criando negócios sustentáveis. Barueri: Manole, 2015.

BARBIERI, C.. Gestão Ambiental Empresarial: conceitos, modelos e instrumentos. 2 ed. São Paulo: Saraiva, 2007.
BARBIERI, J. C.. Gestão ambiental empresarial: conceitos, modelos e instrumentos. São Paulo: Saraiva, 2006.

BEREZAN, O.; RAAB, C.; YOO, M.; LOVE, C.. Sustainable hotel practices and nationality: the impact on guest satisfaction and guest intention to return. International Journal of Hospitality Management, v.34, n.2, p.227-233, 2013. DOI: https://doi.org/10.1016/j.ijhm.2013.03.010

BERG, B. L.. Qualitative Research Methods for the social sciences. California: Allyn \& Bacon, 2001.

BERTUCCl, J.. Metodologia Básica para elaboração de 
trabalho de conclusão de cursos (TCC): ênfase na elaboração de TCC de pós-graduação Lato Sensu. São Paulo: Atlas, 2009.

BIER, F.; BASSAN, D. S.. Responsabilidade social e ambiental: um estudo de caso em uma empresa de tecnologia em Porto Alegre. Colóquio, v.12, n.1, p.149-164, 2015. DOI: https://doi.org/10.26767/coloquio.v12i1.226

BOTELHO, K. T.; DIAS, M. R.; BARBOSA, A. S.; COLALILLO, E. G.; WALCHHÜTTER, S.. Indicadores de sustentabilidade empresarial: um estudo exploratório. Revista Eletrônica Interdisciplinar, v.8, n.2, p.104-16, 2015. DOI: https://doi.org/10.5380/diver.v8i2.45050

CAMPOS, A. C. S.; ESTENDER, A. C. MACEDO, D.. O Ambiente e a Sustentabilidade no Ramo Hoteleiro. Rev. Adm. Unisal, v.5, n.7, p.13-38, 2015.

COHEN, M.; CAVAZOTTE, F. S. C. N.; COSTA, T. M.; FERREIRA, K. C. S.. Responsabilidade Socioambiental Corporativa como Fator de Atração e Retenção para Jovens Profissionais. Braz. Bus. Rev., Vitória, v.14, n.1, p.21-41, 2017. DOI: http://dx.doi.org/10.15728/bbr.2017.14.1.2

CORDAZZO, E. G.; COMONELLI, E. F.; MAZZIONI, S.; MORAES, G. V.. Responsabilidade socioambiental de uma organização sem fins econômicos para o desenvolvimento regional. Revista do Desenvolvimento Regional, Taquara, v.15, n.2, p.151-176, 2018. DOI:

https://doi.org/10.26767/coloquio.v16i2.803

CORREIA, J. J. A.; SILVA, F. E. A.; RODRIGUES, N. R.. Evidenciação socioambiental de empresas siderúrgicas brasileiras entre 2011 e 2015: análise dos relatórios financeiros e de sustentabilidade. Rev. Bras. Gest. Amb. Sustent., v.4, n.8, p.327-341, 2017. DOI: https://doi.org/10.21438/rbgas.040808

DOMINGUES, H.; VALENTIN, T. J.; MIRANDA, G. M. C.. Sócioenvironmental responsibility: the case of a cosmetics industry in the interior of Minas Gerais, Brazil. Research, Society and Development, v.9, n.7, p.1-18, 2020. DOI: https://doi.org/10.33448/rsd-v9i7.3056

DONAIRE, D.. Gestão Ambiental na Empresa. 2 ed. São Paulo: Atlas, 2016.

ELKINGTON, J.. Toward the sustainable corporation: win-win business strategies for sustainable development. Califórnia Management Review, v.36, n.2, p.90-100, 1994. DOI: https://doi.org/10.2307/41165746

FENKER, E. A.; DIEHL, C. A.; ALVES, T. W.; KALINOWSKI, C.. Gestão Ambiental: incentivos, riscos e custos. São Paulo: Atlas, 2015.

FIGUEIREDO, R.; ARAÚJO, E. A.. Desempenho financeiro de empresas listadas no Índice de Sustentabilidade Empresarial (ISE): uma abordagem utilizando método multicritério. Relatórios de Pesquisa em Engenharia de Produção, v.16, n.1, p.1-17, 2016.

FUSS, M.; BARROS, R. T. V.; POGANIETZ, W.. Designing a framework for municipal solid waste management towards sustainability in emerging economy countries: An application to a case study in Belo Horizonte (Brazil). Journal of Cleaner
Production, v.178, p.655-664, 2018. DOI:

https://doi.org/10.1016/i.jclepro.2018.01.051

GIBBS, G.. Análise de Dados Qualitativos. Porto Alegre: Artmed, 2009.

GODOY, A. S.. A pesquisa qualitativa: tipos fundamentais. Revista de Administração de Empresas, São Paulo, v.35, n.3, p.20-29, 1995. DOI: https://doi.org/10.1590/s0034$\underline{75901995000300004}$

JONES, T. M.; HARRISON, J. S.; FELPS, W.. How applying instrumental stakeholder theory can provide sustainable competitive advantage. Academy of Management Review, v.43, n.3, p.371-391, 2018. DOI:

https://doi.org/10.5465/amr.2016.0111.

LOPES, A. C.; LUCA, M. M. M.; GÓIS, A. D.; VASCONCELOS, A. C.. Disclosure socioambiental, reputação corporativa e criação de valor nas empresas listadas na BM\&Fbovespa. Rev. Amb. Cont., v.9, n.1, p.364-382, 2017.

LOUREIRO, C. F. B.. Trajetória e fundamentos da educação ambiental. 4 ed. São Paulo: Cortez, 2012.

MACHADO FILHO, C. P.. Responsabilidade social e governança: o debate das implicações. São Paulo: Pioneira Thomson Learning, 2006.

MAZZUOLI, V. O.; AYALA, P. A.. Cooperação internacional para a preservação do meio ambiente: o direito brasileiro e a Convenção de Aarhus. Revista Direito GV, São Paulo, v.8, n.1, p.297-328, 2012. DOI: https://doi.org/10.1590/s180824322012000100012

MEADOWS, D.; MEADOWS, D.; RANDERS, J.. Más allá de los límites del crecimiento. Madrid: Aguilar, 1992.

MINTZBERG, H.. Renovação radical: uma estratégia para restaurar o equilíbrio e salvar o planeta. Porto Alegre: Bookman, 2015.

MUNCK, L.. Gestão da sustentabilidade nas organizações: um novo agir frente à lógica das competências. São Paulo: Cengage Learning, 2013.

PACHECO, M. R. S.; HELENE, M. E. M.. Atmosfera, fluxos de carbono e fertilização por CO2. Estudos Avançados, São Paulo, v.4, n.9, 1990. DOI: https://doi.org/10.1590/s010340141990000200010

PAIVA, L. B.; ARAÚJO, F. J. A.; LUCA, M. M. M.; VASCONCELOS, A. C.. Práticas de responsabilidade socioambiental e o desempenho em pequenas e médias empresas brasileiras. Gestão \& Regionalidade, v.35, n.106, 2019. DOI: https://doi.org/10.13037/gr.v35i106.5184

PORTELLA, A. R.; OLIVEIRA, M. C.; FERREIRA, D. D. M.; BORBA, J. A.. Responsabilidade socioambiental por meio da missão, visão e valores: um estudo nas 100 maiores empresas de Santa Catarina. Revista Gestão \& Sustentabilidade Ambiental, v.4, n.1, p.217-241, 2015. DOI: https://doi.org/10.19177/rgsa.v4e12015217-241

RIBEIRO, F.; ALVES, T. A.; TAFFAREL, M.; MENON, G.. Responsabilidade social corporativa e o desempenho financeiro no setor de energia elétrica: um estudo com 
modelo de dados em painéis. Gestão \& Regionalidade, v.33, n.99, p.39-54, 2017. DOI:

https://doi.org/10.13037/gr.vol33n99.3987

RIBEIRO, P. E. C.; PUENTE-PALACIOS, K. E.; FERREIRA, T. V. A.. Responsabilidade socioambiental as organizações: uma medida de práticas organizacionais e endosso dos trabalhadores. Revista de Gestão Social e Ambiental, São Paulo, v.9, n.1, p.36-50, 2015. DOI: https://doi.org/10.24857/rgsa.v9i1.947

RODRIGUES, C.; CARNEIRO, A. F.; SILVA, J. M.; DAL MAGRO, E. F.. Gestão e responsabilidade socioambiental: estudo multicaso no setor hoteleiro da cidade Portal da Amazônia. Estudo \& Debate, Lajeado, v.24, n.1, p.42-66, 2017. DOI: https://doi.org/10.22410/issn.1983-036x.v24i1a2017.1066

SACHS, I.. Ecodesenvolvimento: crescer sem destruir. São Paulo: Vértice, 1986.

SCHMIDHEINY, S.. Changing course: a global business perspective on development and the environment. Cambridge: MIT Press, 1992.

SILVA, F. D. S.; VASCONCELOS, J. V. G.; SMITH, E. F. A. R. OLIVEIRA, P. F. M. S.; ABRANTES, J. S.; VALADARES, A. D..
Desempenho socioambiental da empresa WEG S.A por meio da análise do índice de sustentabilidade empresarial (ISE). Revista Científica Multidisciplinar do CEAP, v.2, n.1, 2020a.

SILVA, J. F.; OLIVEIRA, A. M.; RIBEIRO, W. A.. Evidenciação de práticas de responsabilidade socioambiental pelas empresas de energia elétrica à luz da NBCT 15. Refaz, v.7. n.2, 2020 b.

SILVA, S. S.; REIS, R. P.; AMÂNCIO, R.. Paradigmas ambientais nos relatos de sustentabilidade de organizações do setor de energia elétrica. RAM: Rev. Adm. Mackenzie, São Paulo, v.12, n.3, p.146-176, 2011. DOI: https://doi.org/10.1590/s1678-69712011000300007

SOUZA, L. D.; VALADAO JUNIOR, V. M.; MEDEIROS, C. R. O.. Crime corporativo e o discurso da responsabilidade socioambiental: inconsistências, contradições e indiferença no diálogo da corporação com stakeholders. Gest. Prod., São Carlos, v.24, n.4, p.690-703, 2017. DOI: https://doi.org/10.1590/0104-530×1394-17

ZHAO, L.; DU, J.. Certification of environmental corporate social responsibility activities in differentiated duopoly market. Mathematical Problems in Engineering, v.20, n.17, p.1-7, 2017. DOI: https://doi.org/10.1155/2017/2597159

A CBPC - Companhia Brasileira de Produção Científica (CNPJ: 11.221.422/0001-03) detém os direitos materiais desta publicação. Os direitos referem-se à publicação do trabalho em qualquer parte do mundo, incluindo os direitos às renovações, expansões e disseminações da contribuição, bem como outros direitos subsidiários. Todos os trabalhos publicados eletronicamente poderão posteriormente ser publicados em coletâneas impressas sob coordenação da Sustenere Publishing, da Companhia Brasileira de Produção Científica e seus parceiros autorizados. Os (as) autores (as) preservam os direitos autorais, mas não têm permissão para a publicação da contribuição em outro meio, impresso ou digital, em português ou em tradução. 